\section{People with dementia can remember ${ }^{\dagger}$}

\author{
Implications for care
}

\author{
D. D. R. WILLIAMS and JANE GARNER
}

It is generally accepted that we all remember with great clarity and detail highly charged emotional events. Older people remember receiving news of the end of the Second World War and the assassination of John F. Kennedy. A high percentage of people in the UK, and many across the world, will always remember the circumstances in which they received the news of the death of Princess Diana. In addition to excellent recollection of the key event, many other peripheral details are remembered as well. This was described by Brown \& Kulik (1977) as the 'flashbulb' effect.

\section{EMERGING EVIDENCE}

At a common-sense level it is obvious that there is a link between emotion and memory. Strongman (1990) reviewed the evidence and pointed out the paucity of any empirical or theoretical evidence. In contrast, Brown \& Kulik (1977) have provided laboratory evidence that memory is superior for provocative and unusually presented words among lists of neutral target words. This observation was utilised in Sandman's (1993) experiments to improve the memory of people with Alzheimer's disease with a mean Mini-Mental State Examination (MMSE) score of 19. In this small study it was shown that people remembered special or unusual events and that the emotion linked with the event was more likely to be remembered and could facilitate the recollection of factual memory. All those who work with people with dementia are aware that anger can unlock a flow of memory and even severely impaired people can unleash a coherent stream of invective when enraged. In the same way psychotherapists working in this area find that a therapeutic intervention can integrate the memory, if only for a moment (Sinason, 1992).

'See pp. 425-428, this issue.

\section{THE KOBE EARTHQUAKE}

The Kobe earthquake occurred at 05.46 on 17 January 1995. It registered 7.2 on the Richter scale, caused 44000 casualties including more than 6300 deaths and extensive terrestrial and structural damage in the greater Kobe area of Japan. It was noticed that those with Alzheimer's disease who could not recall any events minutes or hours ago, vividly described their own terrible experience of the earthquake. Ikeda et al (1998) are to be congratulated on recognising that the earthquake and its aftermath provided a unique opportunity to explore the association between memory and emotion. In this issue (pp. 425-428) they report their findings about 51 people with probable Alzheimer's disease who were at home when the earthquake occurred. Their memories of the earthquake were assessed at 6 and 10 weeks afterwards and compared with their memories of a magnetic resonance imaging (MRI) scan performed after the earthquake. This comparison was made as the MRI scan sometimes produces transient panic- or anxiety-related reactions. Eighty-six per cent of the subjects remembered the earthquake, whereas only $31 \%$ remembered the MRI scan. All the people who remembered the MRI also remembered the earthquake. People with even mild cognitive dysfunction did not recall the MRI, while subjects with severe dementia frequently recalled the earthquake. Although the tendency to forget the earthquake increased with disease progression, some individuals with advanced dementia remembered the event. The results indicated that what the people remembered was the alarming personal ordeal and not the factual details of the event.

\section{IMPLICATIONS FOR CLINICIANS}

The research findings described by Ikeda et al are an important development in our knowledge of the relationship between memory and emotion. They contain pointers about several aspects of clinical work and the management of people with dementia. These people have islands of memory, which, if discovered and utilised, can have an activating effect and release further memories. Fleming et al (1996), who also found improved memory for emotional material in people in Alzheimer's disease, noted that this lent support to the use of contextual manipulations to increase memory functioning.

On a long-stay ward there is a woman with little sensible conversation and a MMSE score of six. When she is reminded of her job as a housekeeper to a well-known family the dialogue becomes more sensible and meaningful. In instances of physical abuse people with severe dementia can make statements that identify their assailant. The studies from Kobe reinforce what many clinicians have thought to be true, that people with severe dementia sometimes are able to remember traumatic events. This seems to hold true whether the traumatic event occurred before or after the onset of the disease process.

Some work has been undertaken to recover emotional memories in people with few verbal skills. McCloskey (1990) has described in a moving way how she uses music to explore and locate islands of memory and, in a therapeutic way, uses the music of the subjects' youth and happier times to relieve distress and bring comfort and contentment.

Psychotherapists working with people with dementia learn to use words in the individual's personal vocabulary to retell the person's individual stories (Hausman, 1992) so that at a later stage in the disease the therapist can operate as an auxiliary ego to facilitate recall of memories otherwise forgotten. Williams (1997) has described an empathic style of interviewing people with memory difficulties to encourage recollection of events in their lives. Recognition of empathy in the interviewer seems to act as a cue to the individual to recall emotionally important material. Kitwood (1990), in writing of the "malignant social psychology" which surrounds people with dementia, recognises that often functioning is at a worse level than that determined by the dementia, in response to the behaviour and attitude of others. Affective tone is recognised and responded to long after other abilities are lost.

Clearly, more research is needed into this association but at this stage there is 
sufficient evidence emerging to question the current management of people with dementia. The tendency on hard-pressed wards is for them to be managed in a routine way with little to distinguish one day from the next. To decrease the rate of memory loss, more varied meaningful stimulation should be introduced regularly into their pattern of activity. and daily living. Staff need to remember that the person can be reached affectively long after they cease to be able to be reached cognitively, not only by events as major as an earthquake but also by day-to-day occurrences and relationships on the ward.

\section{REFERENCES}

Brown, R. \&ulik, J. (1977) Flashbulb memories Cognition. 5. 73-99.

Fleming, K., Maguire, G., Kim, S., et ol (1996) Memory for emotional stimuli in patients with Alzheimer's disease. Alzheimer's Diseose Clnicol Abstrocts, I, 8.

D. D. R.WILLIAMS, FRCPsych, Cefn Coed Hospital, Swansea; JANE GARNER, FRCPsych, Department of Old Age Psychiatry. Chase Farm Hospital, Enfield

Correspondence: D. D. R.Williams. Consultant Psychiatrist. Cefn Coed Hospital, Swansea SA2 OGH. Tel: 01792561155 . Fax: 01792580740

(First received 7 November 1997, accepted 13 November 1997)

Hausman, C. (1992) Dynamic psychotherapy with elderly demented patients. In Core Giving in Dementia (eds G. M. M. Jones \& B. M. L. Miesen), pp. $181-198$. London: Tavistock/Routledge.

Ikeda, M., Mori, E., Hirono, N., et al (1998) Amnestic people with Alzheimer's disease who remembered the Kobe earthquake. British journol of Psychiotry. 172. 425-428.

Kitwood, T. (1990) The dialectics of dementia: with particular reference to Alzheimer's disease. Ageing and Society. 10. 177-196.

McCloskey, L. J. (1990) The silent heart sings. Reminiscence and life review through music. Generotions. 14. 63-65.
Sandman, C. A. (1993) Memory rehabilitation in Alzheimer's disease: preliminary findings. Clinicol Gerontologist. 13. 19-33.

Sinason, V. (1992) The man who was losing his brain. In Mental Handicop and the Human Condition, pp. 87-110. London: Free Association Books.

Serongman, D.T. (1990) Emotional and memory. In Hondbook of Emotion, Adult Development and Ageing (eds C. Magui \& S. H. McFadden), pp. 133-147. London Academic Press.

Williams, D. D. R. (1997) The psychiatric interview: a different approach in the elderly. Old Age Psychiatrist. 7. 4 . 